\title{
Comparison of maximal muscle strength of elbow flexors and knee extensors between younger and older men with the same level of daily activity
}

This article was published in the following Dove Press journal:

Clinical Interventions in Aging

II April 2013

Number of times this article has been viewed

\author{
Felipe Romano Damas \\ Nogueira' \\ Cleiton Augusto Libardi, ${ }^{1,2}$ \\ Felipe Cassaro Vechin ${ }^{1,2}$ \\ Manoel Emílio Lixandrão' \\ Ricardo Paes de Barros \\ Berton' \\ Thiago Mattos Frota de \\ Souza' \\ Miguel Soares Conceição' \\ Claudia Regina Cavaglieri' \\ Mara Patricia Traina \\ Chacon-Mikahil' \\ 'School of Physical Education, State \\ University of Campinas, ${ }^{2}$ School \\ of Physical Education and Sport, \\ University of São Paulo, São Paulo, \\ Brazil
}

Correspondence: Felipe Romano Damas Nogueira

Laboratory of Exercise Physiology,

School of Physical Education, State

University of Campinas, Av Érico

Veríssimo, 70 I CEP I3083-85I,

PO Box 6134, Campinas, Brazil

Tel +55 I9 352। 6625

Fax +551935216750

Email felipedamasfl@gmail.com
Background: Aging promotes neuromuscular loss, significantly reducing muscle strength. The magnitude of loss of strength seems to be different between the limbs, probably because of differences in activities of daily living (ADL). Therefore, the present study compared the muscle strength of the elbow flexors and knee extensors in younger $(n=7$, mean age $23.3 \pm 1.2$ years $)$ and older ( $\mathrm{n}=5$, mean age $61.8 \pm 2.6$ years) men matched by ADL level.

Methods: The study participants performed maximal concentric, isometric, and eccentric contractions of the elbow flexors and knee extensors using an isokinetic dynamometer following a crossover study design. Changes in the dependent variables were compared using mixed model analysis (limb versus age).

Results: The main results demonstrated that concentric, eccentric, and mean contraction torques for knee extensors were significantly $(P<0.05)$ higher for younger men than for elderly men. On the other hand, no statistically significant difference $(P>0.05)$ was found in concentric, isometric, eccentric, and mean torques for elbow flexors between younger and older individuals.

Conclusion: These results show that elbow flexors maintain better strength than knee extensors through aging, even when comparing individuals with similar ADL levels.

Keywords: aging, sarcopenia, concentric contraction, isometric contraction, eccentric contraction

\section{Introduction}

Advancing age is associated with loss of muscle mass and function. ${ }^{1-4}$ The amount of reduced muscle mass is replaced by an infiltration of conjunctive tissue and fat. ${ }^{2}$ In addition, aging jeopardizes action potential conduction velocity in muscle fibers ${ }^{5}$ and efficiency in recruitment of motor units. ${ }^{6}$ Impaired neuromuscular function as a result of advancing age contributes to significantly reduced muscle strength. ${ }^{7}$ Interestingly, it has been shown that this reduction in muscle strength through aging is greater for the lower limb muscles than for those of the upper limb. ${ }^{8-10}$ However, to date, the reasons for these differences in limb susceptibility to loss of strength due to aging are not well understood.

Lynch et al $^{9}$ studied 703 volunteers aged 19-93 years and, using peak concentric and eccentric torques, demonstrated that aging promoted greater loss of muscle strength in the lower limbs than in the upper limbs. These authors speculated that there is greater disuse of leg muscles than of arm muscles with increasing age. ${ }^{9}$ Similarly, Frontera et $a 1,{ }^{8}$ in a 12 -year longitudinal study, documented that the mean annual reduction in strength was in the range of $1.4 \%-2.5 \%$, with elbow flexors having a 
mean loss of isokinetic strength at $60^{\circ}$ per second of $16.4 \%$ (annual loss approximately 1.4\%) and knee extensors having significantly greater loss of strength $(23.7 \%$, annual loss about $2.0 \%$ ). Candow and Chilibeck ${ }^{10}$ also analyzed elbow flexor and knee extensor torques (among other muscle groups) in young and elderly subjects, and found that strength in the lower body muscles is more affected by age than that of the upper body muscles. The extent to which activities of daily living (ADL) may have influenced the results of these studies is unknown, ${ }^{8,9}$ or whether the younger subjects performed more moderate and strenuous intensity exercise than the older subjects. ${ }^{10}$

It has been shown clearly that ADL and physical activity level can influence the magnitude of muscle strength. ${ }^{11,12}$ Therefore, the ADL level may possibly explain the greater loss of strength in lower limb muscles than in upper limb muscles with aging. However, none of the above-mentioned studies $^{8-10}$ matched participants (young and old) for their ADL level. Equalizing the ADL level, it is possible that age-related loss of strength is similar between elbow flexors and knee extensors.

Therefore, the present study compared maximal strength of the elbow flexors and knee extensors (using maximal concentric, eccentric, isometric, and mean torques) in younger and older men with the same level of ADL. It was hypothesized that young individuals would have more strength in the elbow flexors and knee extensors than their elderly counterparts, and that matching ADL level to age, similar losses of muscle strength could be expected for elbow flexors and knee extensors.

\section{Materials and methods Subjects}

The number of participants required for the present study was determined by sample size estimation utilizing $\mathrm{G}^{*}$ Power (version 3.0.10) ${ }^{13}$ based on data from a previous study ${ }^{9}$ that analyzed the strength of elbow flexors and knee extensors in young and old individuals. The estimation was based on a difference in loss of strength of about $6 \%$ between elbow flexors and knee extensors with aging. We used an $\alpha$ level of 0.05 and a power $(1-\beta)$ of 0.95 . Calculations demonstrated that a total of eight individuals were needed to test our hypothesis.

We recruited 12 healthy men (seven younger and five older subjects) for the present study, and their characteristics are shown in Table 1. The inclusion criteria were: no cardiac disease, arterial hypertension, or diabetes mellitus; no participation in a resistance training program for at least 12 months prior to the study; and no musculoskeletal injuries of the upper or lower extremities. All volunteers were evaluated by a medical doctor and were considered to be able to perform maximal strength tests. All participants provided their informed consent and the study was approved by the ethics committee at our institution. The study was conducted in conformity with the policy statement regarding use of human subjects by the Declaration of Helsinki.

The subjects were asked and reminded not to perform any physical exercise for at least 96 hours before and during the study period. All volunteers were evaluated for their physical activity level using the Baecke questionnaire. ${ }^{14}$ This questionnaire evaluates the ADL level for the past 12 months, taking into account occupational physical activities, physical exercises practiced during leisure time, and physical activities practiced during leisure time and locomotion (excluding physical exercise). ${ }^{15}$ Limb circumference was measured by an experienced investigator using a constant-tension tape (with $1 \mathrm{~mm}$ resolution) at the mid portion of each limb (at the middle point between the acromion and the olecranon for elbow flexors, and at the middle point between the inguinal ligament and the top edge of the patella for knee extensors). The circumference of the elbow flexors and knee extensors was defined as the perpendicular perimeter of the longitudinal axis of the humerus and femur, respectively. The investigator measured the circumference three times for each limb while the volunteer stood with arms relaxed beside the body. The average of three measurements for elbow flexors and knee extensors was used as the circumference value.

\section{Experimental protocol}

All volunteers were familiarized with the study equipment and tests before collection of data. Three days later, the

Table I Participant characteristics and Baecke score

\begin{tabular}{llllllll}
\hline & $\begin{array}{l}\text { Age } \\
(\text { years })\end{array}$ & $\begin{array}{l}\text { Body mass } \\
(\mathbf{k g})\end{array}$ & $\begin{array}{l}\text { Height } \\
(\mathbf{m})\end{array}$ & $\begin{array}{l}\text { BMI } \\
\left(\mathbf{k g} / \mathbf{m}^{2}\right)\end{array}$ & $\begin{array}{l}\text { EF Cir } \\
(\mathbf{c m})\end{array}$ & $\begin{array}{l}\text { KE Cir } \\
(\mathbf{c m})\end{array}$ & $\begin{array}{l}\text { Baecke } \\
\mathbf{s c o r e}\end{array}$ \\
\hline Young $(\mathrm{n}=7)$ & $23.3 \pm 1.2$ & $77.6 \pm 6.2$ & $1.79 \pm 0.03$ & $24.4 \pm 2.1$ & $31.5 \pm 2.2$ & $54.7 \pm 2.6$ & $5.4 \pm 0.3$ \\
Old $(\mathrm{n}=5)$ & $61.8 \pm 2.6^{*}$ & $79.2 \pm 4.5$ & $1.72 \pm 0.04$ & $26.8 \pm 1.5$ & $31.2 \pm 1.7$ & $53.2 \pm 1.6$ & $4.7 \pm 0.5$ \\
\hline
\end{tabular}

Notes: Mean \pm standard error of the mean. *Significantly different $(P<0.05)$ from younger group.

Abbreviations: BMI, body mass index; Cir, limb circumference; EF, elbow flexors; KE, knee extensors. 
strength protocols for elbow flexors and knee extensors were performed in a random and counterbalanced order between ages and limbs, with two weeks of rest between the elbow flexor and knee extensor tests according to a crossover design. All tests were performed using the nondominant limb (determined by the writing hand and leg used to kick a ball with precision ${ }^{16}$ ) in an isokinetic dynamometer (Biodex System 4 Pro, Biodex Medical Systems, Shirley, NY, USA) to standardize the velocity of execution and range of motion and also to quantify the peak torque. A warm-up consisting of two sets of three repetitions (concentric/concentric) at $90^{\circ}$ per second was performed before all procedures on the isokinetic dynamometer. The volunteers were positioned in the dynamometer chair and fixed by straps at the chest, lap, and leg to limit extraneous movement. For elbow flexor exercise, the shoulder joint was positioned at $90^{\circ}$ of flexion and $0^{\circ}$ of abduction, and the forearm was supinated, holding the lever arm of the dynamometer. For knee extensor exercise, the hip joint was positioned at $85^{\circ}$ of flexion with the arms folded in front of the chest. ${ }^{17}$ The dynamometer rotation axis was visually aligned with the elbow joint or knee joint for the elbow flexor and knee extensor exercises, respectively. All subjects were verbally encouraged to achieve maximum strength at each strength test (concentric, isometric, and eccentric), and the maximum torque developed was calculated by the software of the isokinetic dynamometer.

\section{Concentric torque}

To quantify maximum concentric contraction torque, the volunteers performed a set of four maximum concentric contractions at $60^{\circ}$ per second for the elbow flexors and the knee extensors. ${ }^{17}$ The range of motion of each contraction was $60^{\circ}\left(20^{\circ}-80^{\circ}\right.$ for elbow flexors; $90^{\circ}-30^{\circ}$ for knee extensors $)$. Anatomical zero for both limbs was considered to be $0^{\circ} .{ }^{17}$ This procedure was selected because older subjects could have a reduced range of motion, ${ }^{18}$ so they might not reach the $120^{\circ}$ range of motion, as other study with young subjects applied. ${ }^{19}$ Even with a $90^{\circ}$ range of motion, previous study have shown that the elderly may have problems reaching a full range of motion. ${ }^{20}$ The maximum contraction torque for four concentric contractions was used for further analysis.

\section{Isometric torque}

Maximum isometric contraction torque was achieved by three maximal isometric attempts at $50^{\circ}$ for the elbow flexors and $60^{\circ}$ for the knee extensors, ${ }^{17}$ with 60 seconds of rest between attempts. The maximum isometric contraction torque of three attempts was used for further analysis.

\section{Eccentric torque}

A set of six maximum eccentric repetitions at $90^{\circ}$ per second in the isokinetic dynamometer was used to quantify the maximum eccentric contraction torque of the elbow flexors and knee extensors. The range of motion was the same as for the concentric test, ie, $60^{\circ}\left(80^{\circ}-20^{\circ}\right.$ for elbow flexors and $30^{\circ}-90^{\circ}$ for knee extensors). Anatomical zero for both limbs was considered to be $0^{\circ} \cdot{ }^{17}$ Immediately before each maximum eccentric contraction, the volunteers performed one second of isometric contraction at the initial position to warrant maximal eccentric contraction since the beginning of the movement. The movement return was realized passively at $5^{\circ}$ per second, resulting in 12 seconds of rest between contractions. Maximum eccentric contraction torque developed at the set was used for further analysis.

\section{Mean torque}

The arithmetic mean for the concentric, isometric, and eccentric contraction torques was calculated for each limb (elbow flexors and knee extensors) and each age group (young and old) in order to establish the general strength of each limb. The results are presented as mean torque values.

\section{Reliability}

The reliability of the strength measures was established comparing two baseline measures separated by three days. Our calculations showed a high intraclass correlation coefficient (0.995-0.998) and a low coefficient of variation $(3.4 \%-5.4 \%)$.

\section{Statistical analysis}

Independent-samples $t$-tests were used to compare the anthropometric parameters, subject age, and ADL level calculated by the Baecke questionnaire. Levene's test was used to evaluate the equality of variances in independent samples. To compare the changes in dependent variables between muscle strength and age, we used a mixed model analysis, with muscle groups (elbow flexors and knee extensors) and age (young and old) as fixed factors and subjects as a random factor. When a significant $F$ was obtained, the Tukey post hoc test was used to identify any significant differences. Statistical significance was set at $P<0.05$. All data are presented as the mean \pm standard error of the mean.

\section{Results \\ Concentric torque}

It was demonstrated significant main effects for muscle, age, and interaction of muscle versus age $(P<0.001, P=0.004$, and 
$P=0.004$, respectively). Concentric torque for the knee extensors in the young and old age groups was significantly greater than that of the elbow flexors ( $P<0.001$ and $P=0.001$, respectively). Concentric torque for the elbow flexors was similar between the age groups (younger, $43.3 \pm 2.6 \mathrm{Nm}$ (Newton*meter); older, $45.3 \pm 6.9 \mathrm{Nm} ; P=0.93)$. However, for concentric torque of the knee extensors, the older group showed significantly lower values than the younger group $(156.2 \pm 15.4 \mathrm{Nm}$ versus $208.3 \pm 10.4 \mathrm{Nm}$, respectively, $P=0.002$, Figure 1 ).

\section{Isometric torque}

Analysis of isometric torque for elbow flexors and knee extensors in the younger and older age groups showed only a significant main muscle effect $(P<0.001$; age, $P=0.889$ and interaction of muscle versus age, $P=0.616)$. The isometric torque of the knee extensors for the young and elderly (210.9 $\pm 11.1 \mathrm{Nm} ; 203.4 \pm 9.2 \mathrm{Nm}$, respectively) was significantly $(P<0.001$ for both) greater than that of elbow flexors $(57.2 \pm 4.5 \mathrm{Nm}$ and $60.3 \pm 9.0 \mathrm{Nm}$, respectively).

\section{Eccentric torque}

Mixed-model analysis demonstrated significant effects of muscle, age, and interaction of muscle versus age $(P<0.001$, $P=0.043$. and $P=0.02$, respectively). Eccentric torque for the knee extensors in both age groups was significantly greater than for elbow flexors in younger and older men $(P<0.001$ for both). Figure 1 shows that the eccentric torque for elbow flexors in the younger and older age groups was similar $(62.0 \pm 3.8 \mathrm{Nm}$ and $63.8 \pm 8.9 \mathrm{Nm}$, respectively, $P=0.972)$; however, eccentric torque for knee extensors in the younger men $(278.7 \pm 16.1 \mathrm{Nm})$ was significantly $(P=0.008)$ greater than that in the older men $(268.9 \pm 10.1 \mathrm{Nm})$.

\section{Mean torque}

Significant effects of muscle, age, and an interaction of muscle versus age $(P<0.001, P=0.023$, and $P=0.038$, respectively) were found for mean torque. Mean torque for the knee extensors was significantly greater than that for elbow flexors in both young and older men $(P<0.001$ for both). Figure 2 shows that mean torque for elbow flexors was similar between the age groups (young, $54.2 \pm 3.5 \mathrm{Nm}$; old, $56.4 \pm 8.2 \mathrm{Nm} ; P=0.931)$. However, mean torque for knee extensors in older men $(209.5 \pm 10.9 \mathrm{Nm})$ was significantly $(P=0.01)$ lower than that in young men $(232.6 \pm 11.2 \mathrm{Nm}$, Figure 2).

\section{Discussion}

The present study investigated the hypothesis that, matching the ADL level of younger and older men, loss of muscle strength due to aging should be similar between lower and upper limb muscles. However, the results show that elbow flexor strength did not vary with advancing aging, but that knee extensors had significantly less strength in older men than in young men. Thus, our results document that even with a similar ADL level; the upper limbs maintain better muscle strength than do the lower limbs with aging.

Participant characteristics did not differ between the age groups (Table 1), with the younger and older groups having the same body mass, height, body mass index, elbow flexor and knee extensor circumferences, and Baecke scores. This is important, and highlights the need for standardization with regard to the main comparison in the present study, ie, elbow flexor and knee extensor strength between younger and older subjects with the same level of ADL. Analyzing the muscle strength data (ie, concentric, isometric, eccentric, and mean contraction torques), it was found that younger and older men showed similar elbow flexor strength. This is consistent with previous research in men ${ }^{18,20,21}$ and women ${ }^{22}$ demonstrating that younger and older individuals do not differ in isometric strength of the elbow flexors. With regard to eccentric strength in the elbow flexors, Lynch et $\mathrm{al}^{9}$ documented results similar to those of the present study, ie,

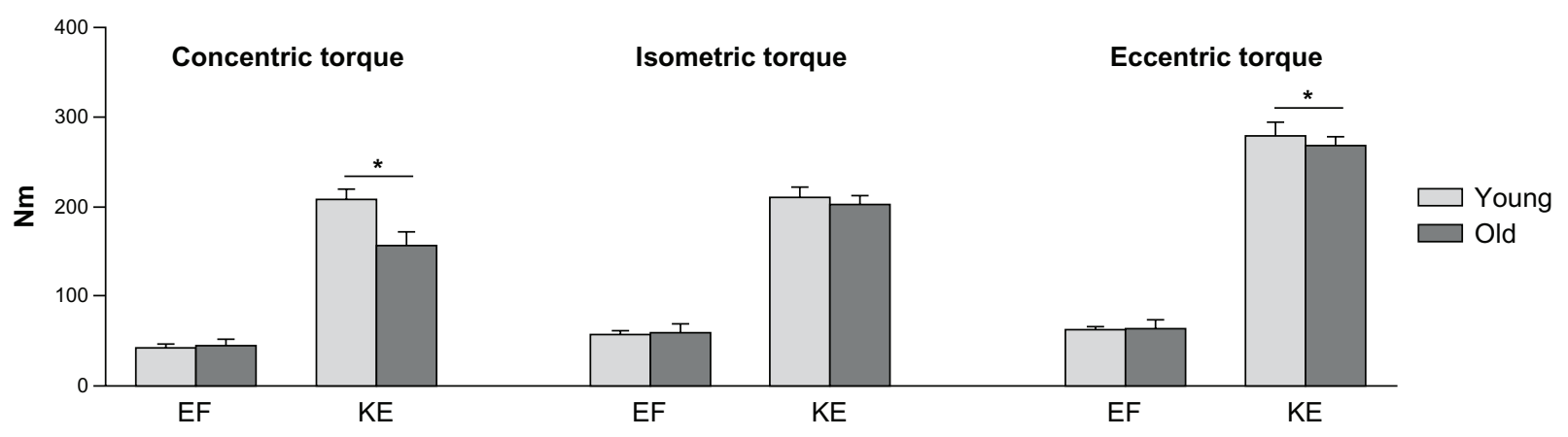

Figure I Concentric, isometric, and eccentric contraction torques for elbow flexors (EF) and knee extensors (KE) in younger and older men. Note: *Significant difference $(P<0.05)$ between the two age groups. 


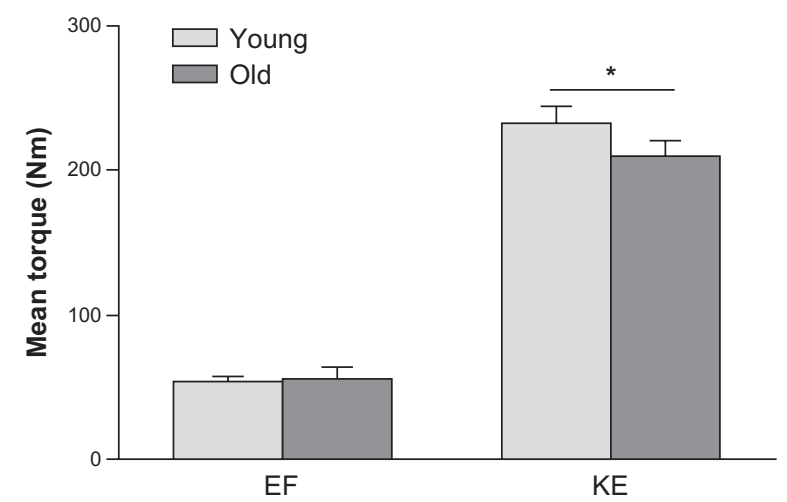

Figure 2 Mean contraction torques for elbow flexors (EF) and knee extensors (KE) in younger and older men.

Note: *Significant difference $(P<0.05)$ between the two age groups.

no difference between eccentric strength of the elbow flexors in younger (20-29 years) and older women (60-79 years). When the same comparison was made between younger (about 19 years) and middle-aged men (about 48 years), also no difference in isometric strength of the elbow flexors was found. ${ }^{23}$ However, conflicting results have been found in other studies showing significant loss of elbow flexor strength in men as a result of aging. ${ }^{8} 9$ These contradictory results might reflect different ADL levels in the age groups included in these studies. ${ }^{8,9}$ It is possible that the similar levels of ADL in the age groups included in the present study could have been responsible for maintenance of elbow flexor strength with aging.

In our study, analysis of concentric, eccentric, and mean contraction torques of the knee extensors revealed important differences between the age groups, ie, older men showed lower concentric, eccentric, and mean contraction torques than young men. Only isometric strength of the knee extensors showed no difference between the age groups. The method used to analyze isometric torque in this work (testing at a single fixed angle, ie, $50^{\circ}$ for the elbow flexors and $60^{\circ}$ for the knee extensors) might have influenced the results. It has been suggested that the pennation angle decreases with aging: ${ }^{9}$ such that aging significantly affects muscle architecture. ${ }^{24}$ Muscle architecture, eg, pennation angle and fascicle length, can change the optimum angle of peak torque. ${ }^{25}$ Therefore, isometric torques at fixed angles might not precisely reflect peak torques in younger or older subjects. Accordingly, it has been suggested that age deficits in isometric torque are angle-specific. ${ }^{26}$ On the other hand, peak eccentric and concentric contraction torques measured dynamically show lower values in older men than in younger men. Altogether, from the results presented (ie, for concentric, eccentric, and mean contraction torque), it is reasonable to suggest that aging promotes major losses in knee extensor strength even with the same level of ADL. The present study demonstrated about $25.0 \%$ of loss in concentric strength of the knee extensors (measure at $60^{\circ}$ per second) in older men compared with younger men. A similar degree of loss was reported by Candow and Chilibeck, ${ }^{10}$ who also measured peak isokinetic concentric torque at $60^{\circ}$ per second for the knee extensors and found an approximate torque loss of $25.3 \%$ comparing younger and older subjects. Lynch et $\mathrm{al}^{9}$ observed a difference of approximately $23.3 \%$ in concentric strength of the knee extensors (at $30^{\circ}$ per second) for younger (20-29 years) and older men (60-69 years). Also analyzing concentric strength of the knee extensors at $60^{\circ}$ per second, Frontera et $\mathrm{al}^{8}$ showed a loss with aging of about $2.0 \%$ per year. These authors demonstrated that, over a period of 12 years, men had a loss of concentric strength in the knee extensors of about $23.7 \%$. Also consistent with the present study, Balagopal et al ${ }^{27}$ documented that isokinetic strength of the quadriceps (the main muscle group involved in knee extension) and strength of the knee extensors measured by one repetition maximum, decreased significantly with age (23 years versus 77 years). In addition, Ploutz-Snyder et $\mathrm{al}^{28}$ demonstrated that concentric and eccentric strength in the knee extensors were lower in older than in younger women.

Interestingly, the present study demonstrated that knee extensor strength in younger men was significantly greater than that in older men, but that elbow flexor strength did not differ between the age groups, indicating that aging modulates muscle strength of the lower and upper limbs in different ways. Similar results have been found in previous studies, demonstrating that with aging, lower limb muscles (eg, knee extensors) show greater loss of muscle strength than the upper limbs (eg, elbow flexors). ${ }^{8-10,29-31}$ Most of the previous studies have considered the level of ADL relevant when interpreting their results. The novelty of the present study is that the same results were found even when matching older and younger men for their level of ADL. It has been proposed that aging may induce more inherent morphological changes in the knee extensors than in the elbow flexors, ${ }^{29}$ ie, leg muscles might be more susceptible to loss of lean mass ${ }^{32,33}$ and might suffer major changes in muscle contractile properties, connective tissue, and muscle architecture (eg, pennation angle) than arm muscles. ${ }^{9}$ Further, it is possible that use of the legs in ADL is reduced to a greater extent than use of arm muscles. ${ }^{8}$ One limitation of the present study is that our Baecke questionnaire on ADL does not segregate frequency and intensity of daily use of the arms and legs. In fact, this has been proposed 
before $^{10,34}$ and might also explain the results of the present study, in that older individuals could supplement weaker lower body movements (such as rising from a chair) with contraction of the upper limb muscles. Future studies investigating the level and intensity of ADL in the arms and legs separately would be helpful to clarify these speculations.

The results of the present study are relevant in the context of physical training and health. For example, strength training programs should be structured with greater emphasis on gains in lower limb strength, given that the strength of the knee extensor muscles predicts levels of dependency and survival. ${ }^{12,35}$

We conclude that even when comparing younger and older men with similar levels of daily life activities, the elbow flexors maintain better strength than the knee extensors.

\section{Acknowledgment}

The authors extend their thanks to all volunteers who participated in this study.

\section{Disclosure}

The authors declare no financial support or relationship that might pose any conflicts of interest in this work.

\section{References}

1. Lexell J, Taylor CC, Sjostrom M. What is the cause of the ageing atrophy? Total number, size and proportion of different fiber types studied in whole vastus lateralis muscle from 15- to 83-year-old men. J Neurol Sci. 1988;84(2-3):275-294.

2. Lexell J. Human aging, muscle mass, and fiber type composition. J Gerontol A Biol Sci Med Sci. 1995;50 Spec No:11-16.

3. Lang T, Streeper T, Cawthon P, Baldwin K, Taaffe DR, Harris TB. Sarcopenia: etiology, clinical consequences, intervention, and assessment. Osteoporos Int. 2010;21(4):543-559.

4. Deschenes MR. Effects of aging on muscle fibre type and size. Sports Med. 2004;34(12):809-824.

5. Bazzucchi I, Marchetti M, Rosponi A, et al. Differences in the force/endurance relationship between young and older men. Eur J Appl Physiol. 2005;93(4):390-397.

6. Lemmer JT, Hurlbut DE, Martel GF, et al. Age and gender responses to strength training and detraining. Med Sci Sports Exerc. 2000; 32(8):1505-1512.

7. Metter EJ, Conwit R, Tobin J, Fozard JL. Age-associated loss of power and strength in the upper extremities in women and men. $J$ Gerontol $A$ Biol Sci Med Sci. 1997;52(5):B267-B276.

8. Frontera WR, Hughes VA, Fielding RA, Fiatarone MA, Evans WJ, Roubenoff R. Aging of skeletal muscle: a 12-yr longitudinal study. J Appl Physiol. 2000;88(4):1321-1326.

9. Lynch NA, Metter EJ, Lindle RS, et al. Muscle quality. I. Age-associated differences between arm and leg muscle groups. J Appl Physiol. 1999; 86(1):188-194.

10. Candow DG, Chilibeck PD. Differences in size, strength, and power of upper and lower body muscle groups in young and older men. J Gerontol A Biol Sci Med Sci. 2005;60(2):148-156.

11. Kuh D, Bassey EJ, Butterworth S, Hardy R, Wadsworth ME. Grip strength, postural control, and functional leg power in a representative cohort of British men and women: associations with physical activity, health status, and socioeconomic conditions. J Gerontol A Biol Sci Med Sci. 2005;60(2):224-231.
12. Rantanen T, Era P, Heikkinen E. Physical activity and the changes in maximal isometric strength in men and women from the age of 75 to 80 years. J Am Geriatr Soc. 1997;45(12):1439-1445.

13. Faul F, Erdfelder E, Lang AG, Buchner A. G*Power 3: a flexible statistical power analysis program for the social, behavioral, and biomedical sciences. Behav Res Methods. 2007;39(2):175-191.

14. Florindo AA, Latorre MRDO. Validação e reprodutibilidade do questionário de Baecke de avaliação da atividade física habitual em homens adultos. [Validation and reliability of the Baecke questionnaire for the evaluation of habitual physical activity in adult men]. Rev Bras Med Esporte. 2003;9(3):121-128. Portuguese.

15. Baecke JA, Burema J, Frijters JE. A short questionnaire for the measurement of habitual physical activity in epidemiological studies. Am J Clin Nutr. 1982;36(5):936-942.

16. Saka T, Akova B, Yazici Z, Sekir U, Gür H, Ozarda Y. Difference in the magnitude of muscle damage between elbow flexors and knee extensors eccentric exercises. J Sports Sci Med. 2009;8(1):107-115.

17. Chen TC, Lin KY, Chen HL, Lin MJ, Nosaka K. Comparison in eccentric exercise-induced muscle damage among four limb muscles. Eur J Appl Physiol. 2011;111(2):211-223.

18. Lavender AP, Nosaka K. Comparison between old and young men for changes in makers of muscle damage following voluntary eccentric exercise of the elbow flexors. Appl Physiol Nutr Metab. 2006; 31(3):218-225.

19. Barroso R, Roschel H, Ugrinowitsch C, Araujo R, Nosaka K, Tricoli V. Effect of eccentric contraction velocity on muscle damage in repeated bouts of elbow flexor exercise. Appl Physiol Nutr Metab. 2010; 35(4):534-540.

20. Lavender AP, Nosaka K. Responses of old men to repeated bouts of eccentric exercise of the elbow flexors in comparison with young men. Eur J Appl Physiol. 2006;97(5):619-626.

21. Chapman DW, Newton MJ, McGuigan MR, Nosaka K. Comparison between old and young men for responses to fast velocity maximal lengthening contractions of the elbow flexors. Eur J Appl Physiol. 2008; 104(3):531-539.

22. Clarkson PM, Dedrick ME. Exercise-induced muscle damage, repair, and adaptation in old and young subjects. J Gerontol. 1988; 43(4):M91-M96.

23. Lavender AP, Nosaka K. Changes in markers of muscle damage of middle-aged and young men following eccentric exercise of the elbow flexors. J Sci Med Sport. 2008;11(2):124-131.

24. Narici MV, Maganaris CN, Reeves ND, Capodaglio P. Effect of aging on human muscle architecture. J Appl Physiol. 2003;95(6):2229-2234.

25. Brughelli M, Cronin J, Nosaka K. Muscle architecture and optimum angle of the knee flexors and extensors: a comparison between cyclists and Australian Rules football players. J Strength Cond Res. 2010; 24(3):717-721.

26. Lanza IR, Towse TF, Caldwell GE, Wigmore DM, Kent-Braun JA. Effects of age on human muscle torque, velocity, and power in two muscle groups. J Appl Physiol. 2003;95(6):2361-2369.

27. Balagopal P, Rooyackers OE, Adey DB, Ades PA, Nair KS. Effects of aging on in vivo synthesis of skeletal muscle myosin heavy-chain and sarcoplasmic protein in humans. Am J Physiol. 1997;273(4 Pt 1): E790-E800.

28. Ploutz-Snyder LL, Giamis EL, Formikell M, Rosenbaum AE. Resistance training reduces susceptibility to eccentric exercise-induced muscle dysfunction in older women. J Gerontol A Biol Sci Med Sci. 2001; 56(9):B384-B390.

29. Grimby G, Danneskiold-Samsoe B, Hvid K, Saltin B. Morphology and enzymatic capacity in arm and leg muscles in 78-81 year old men and women. Acta Physiol Scand. 1982;115(1):125-134.

30. Frontera WR, Hughes VA, Lutz KJ, Evans WJ. A cross-sectional study of muscle strength and mass in 45- to 78-yr-old men and women. J Appl Physiol. 1991;71(2):644-650.

31. Klitgaard H, Mantoni M, Schiaffino S, et al. Function, morphology and protein expression of ageing skeletal muscle: a cross-sectional study of elderly men with different training backgrounds. Acta Physiol Scand. 1990;140(1):41-54. 
32. Aniansson A, Hedberg M, Henning GB, Grimby G. Muscle morphology, enzymatic activity, and muscle strength in elderly men: a follow-up study. Muscle Nerve. 1986;9(7):585-591.

33. Aniansson A, Sperling L, Rundgren A, Lehnberg E. Muscle function in 75-year-old men and women. A longitudinal study. Scand J Rehabil Med Suppl. 1983;9:92-102.
34. Macaluso A, De Vito G. Muscle strength, power and adaptations to resistance training in older people. Eur J Appl Physiol. 2004; 91(4):450-472.

35. Schroll M, Avlund K, Davidsen M. Predictors of five-year functional ability in a longitudinal survey of men and women aged 75 to 80 . The 1914-population in Glostrup, Denmark. Aging (Milano). 1997; 9(1-2):143-152.

\section{Publish your work in this journal}

Clinical Interventions in Aging is an international, peer-reviewed journal focusing on evidence-based reports on the value or lack thereof of treatments intended to prevent or delay the onset of maladaptive correlates of aging in human beings. This journal is indexed on PubMed Central, MedLine, the American Chemical Society's 'Chemical Abstracts

\section{Dovepress}

Service' (CAS), Scopus and the Elsevier Bibliographic databases. The manuscript management system is completely online and includes a very quick and fair peer-review system, which is all easy to use. Visit $\mathrm{http}: / /$ www.dovepress.com/testimonials.php to read real quotes from published authors.

Submit your manuscript here: http://www.dovepress.com/clinical-interventions-in-aging-journal 